\title{
Thermal Properties of Ester Based Thermoplastic Polyurethane/ Polyester Ionomer Blends
}

\author{
Byeong Cheol Kim, Vinh Khanh NGuyen, Myung Yung JeOnG, ${ }^{*}$ and Dai Soo LEE ${ }^{\dagger}$ \\ Faculty of Chemical Engineering and Technology, Research Center of Industrial Technology, \\ Chonbuk National University, Chonju 561-756, Korea \\ *ETRI, Taejon 305-350, Korea
}

(Received January 7, 2002; Accepted October 11, 2002)

KEY WORDS Polyurethane / Polyester Ionomer / Crystallization / Thermal Property / Blends /

Thermoplastic polyurethane (TPU) has various applications. TPU is a linear segmented block copolymer composed of soft and hard segments which undergo phase seperation..$^{1-3}$ The properties of soft segment are determined by the types and molecular weights of polyols while properties of hard segments by the types of diisocyanate and chain extender. Thus, the properties of TPU may be adjusted by raw material and microphase seperation of soft segments and hard segments. Another method to control the properties of polyurethane is the introduction of ionic groups into soft or hard segments. Polymers with ionic groups in the main chain or side chain are called ionomers and show interesting properties due to ionic groups. ${ }^{4}$ Ionomers are usually prepared via copolymerization of ionizable comonomers. There are many papers on the enhancement of compatibilty of polymer blends using ionomers due to interactions of ion-ion or iondipole. $^{5-8}$ For modification of TPU, blends of TPU, and polyester ionomer (PETI) were studied from view points of exchange reaction, miscibility between TPU and PETI, and ionic conductivity of the blends. To elucidate the characteristics of blends, morphology and thermal properties of the blends were investigated and the findings are reported in this paper.

\section{EXPERIMENTAL}

All polymers in this study were commercial products (Table I). Melt blends of an ester based TPU and a PETI (M-TPU/PETI) were prepared using single screw extruder (length-to-diameter ratio of 24 and barrel diameter of $40 \mathrm{~mm}$ ) at $200^{\circ} \mathrm{C}$. TPU and PETI are sensitive to moistures and thus were dried in a vacuum oven at $40^{\circ} \mathrm{C}$ for $12 \mathrm{~h}$ before melt mixing. PETI in the TPU/PETI blends was varied from 0 to $30 \%$ by weight. Solution blends of the TPU and the PETI (STPU/PETI) were prepared using a cosolvent, dimethyl formamide (DMF).

Cryogenically fractured surfaces of the blends were etched with water to dissolve water soluble PETI and coated with gold in vacuum after drying and observed with a scanning electron microscope (SEM, Hitachi X-650). Thermal properties of the blends were studied by a differential scanning calorimeter (DSC) (DSC 910 from DuPont Instruments equipped with TA2000). To control the thermal history, all samples were heated to $220^{\circ} \mathrm{C}$, maintained for $3 \mathrm{~min}$, and cooled at $-5^{\circ} \mathrm{C} \mathrm{min}^{-1}$ in DSC. The samples were quenched to $-120^{\circ} \mathrm{C}$ after exothermic peaks due to

Table I. Characteristics of raw materials

\begin{tabular}{|c|c|c|c|}
\hline Material & Manufacturer & Grade & Characteristics \\
\hline $\begin{array}{l}\text { Ester based } \\
\text { Thermoplastic } \\
\text { polyurethane (TPU) }\end{array}$ & Hosung Chemex & $5090 \mathrm{~A}$ & $\begin{array}{l}M_{\mathrm{w}}: 3.6 \times 10^{5} \\
M_{\mathrm{n}}: 1.4 \times 10^{5} \\
\text { Shore A hardness: } 90\end{array}$ \\
\hline $\begin{array}{l}\text { Ionomer containing } \\
\text { sodiosulfo substituents } \\
\text { attached to amorphous } \\
\text { linear polyester (PETI) }\end{array}$ & $\begin{array}{l}\text { Eastman } \\
\text { Chemical }\end{array}$ & AQ-55 & $\begin{array}{l}M_{\mathrm{n}}: 1.5 \times 10^{4} \\
\text { Ion content }(\mathrm{wt} \%): 10.7\end{array}$ \\
\hline
\end{tabular}

${ }^{\dagger}$ To whom correspondence should be addressed. 


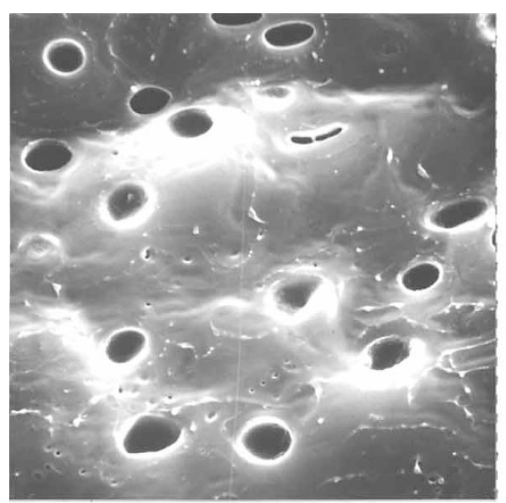

(a)

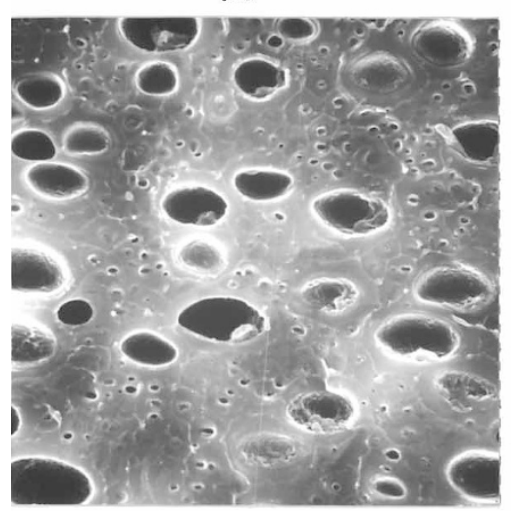

(b)

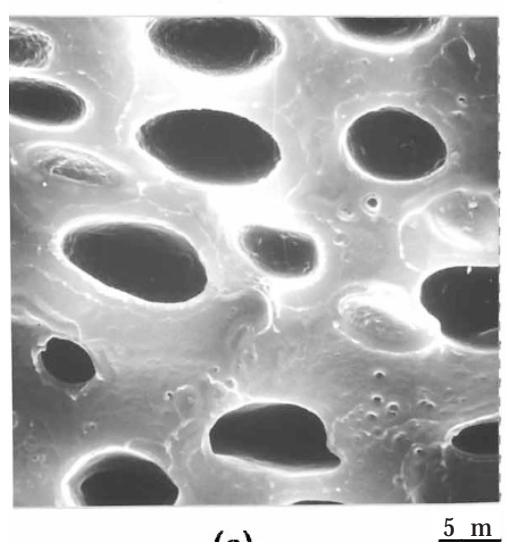

(c)

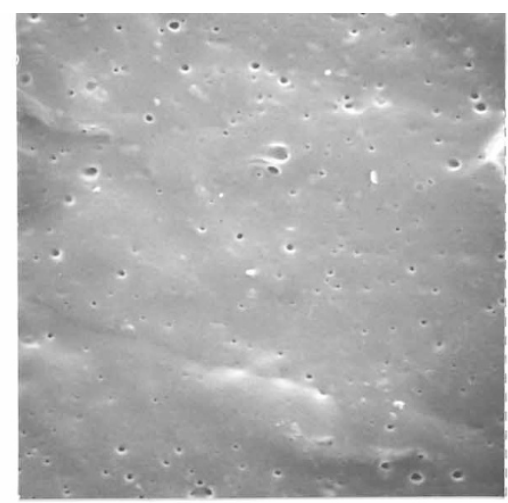

(d)

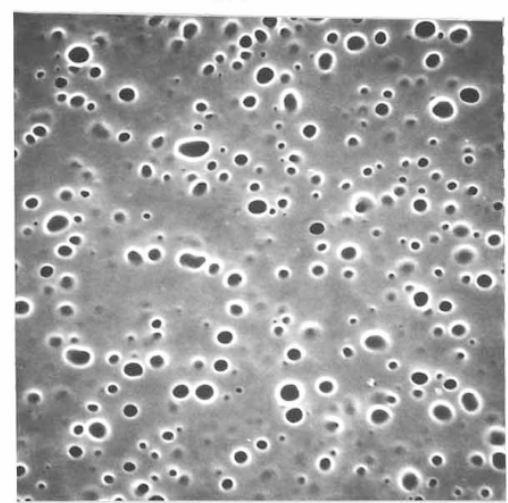

(e)

$2 \mu \mathrm{m}$

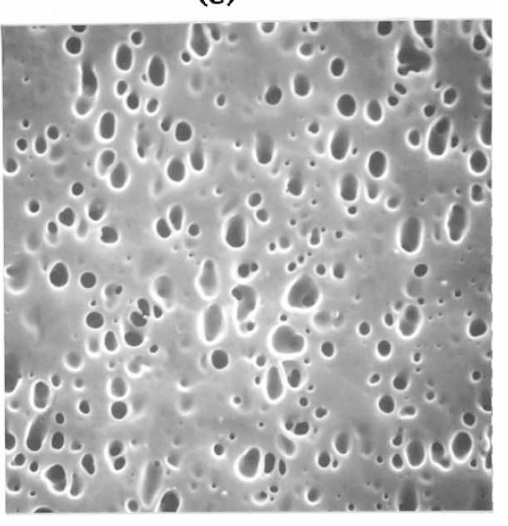

(f) $\underline{2 \mu \mathrm{m}}$

Figure 1. SEM of cryogenically fractured surfaces of various TPU/PETI blends: (a) S-TPU/PETI $=90 / 10$; (b) S-TPU/PETI $=80 / 20$; (c) S-TPU/PETI =70/30; (d) M-TPU/PETI = 90/10; (e) M-TPU/PETI = 80/20; (f) M-TPU/PETI = 70/30.

crystallization of the blends leveled off, which were reheated from $-100^{\circ} \mathrm{C}$ to $220^{\circ} \mathrm{C}$ at $10^{\circ} \mathrm{C} \mathrm{min}^{-1}$ to check thermal transition behavior in nitrogen gas flow. Ionic conductivities of the TPU/PETI blends were measured with a dielectric analyzer (DEA) (DEA 2980 equipped with TA2000). Temperature sweeps for the samples were made with a DEA from $-100^{\circ} \mathrm{C}$ to $80^{\circ} \mathrm{C}$ at $0.1 \mathrm{~Hz}$ under nitrogen gas flow.

\section{RESULTS AND DISCUSSION}

Figure 1 shows SEM of cryogenically fractured surfaces of TPU/PETI blends. As specimens were etched with water to remove water soluble PETI in the fracture surface, holes in the pictures are believed to represent the discrete phase of water soluble PETI. In a, b, and $\mathrm{c}$ of Figure 1, the particle sizes of the PETI in the STPU/PETI blends are 5-10 $\mu \mathrm{m}$ while those for PETI of the M-TPU/PETI blends less than $2 \mu \mathrm{m}$ in Figure 1d, $1 \mathrm{e}$, and 1f. There are many papers on exchange reactions in melts between condensation polymers such as polyester, polyamide, and polycarbonate. ${ }^{9-12}$ Products of exchange reactions usually improve compatibility of the polymer blends. According to Kricheldorf, monodisperse hard segment model compounds of TPU undergoes exchange reactions by thermal treatments and resulted in polydisperse compounds. ${ }^{13}$ Exchange reactions between the TPU and the PETI may occur 


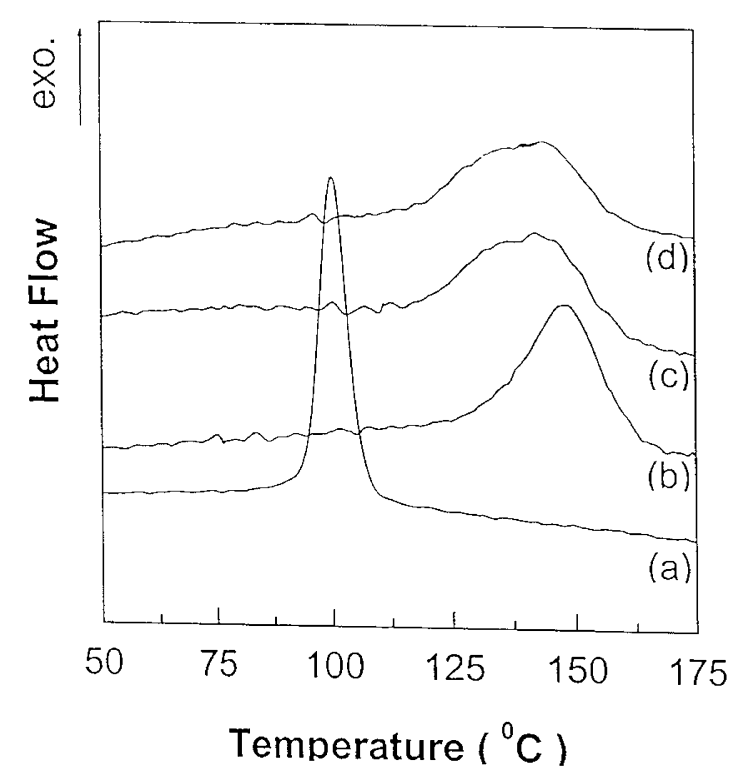

Figure 2. DSC thermograms of various TPU/PETI blends obtained by cooling from $220^{\circ} \mathrm{C}$ at $5{ }^{\circ} \mathrm{Cmin}^{-1}$ : (a) TPU; (b) MTPU/PETI $=90 / 10$; (c) M-TPU/PETI = 80/20; (d) M-TPU/PETI = $70 / 30$.

during melt mixing of the M-TPU/PETI blends. The finer dispersion of PETI in the melt blends compared with the PETI in the solution blends is attributable to compatibilizing effects of exchange reaction products. The morphology of polymer blend is generally determined by miscibility, thermal history, and shear force applied for the mixing to prepare blends. ${ }^{14}$ Thus decrease of particle size of discrete phase in the MTPU/PETI blends may be attributable to different shear force as well as different thermal history of the blends to induce exchange reactions.

In Figure 2, DSC thermograms of the M-TPU/PETI blends obtained by cooling from $220^{\circ} \mathrm{C}$ at $5{ }^{\circ} \mathrm{C} \mathrm{min}^{-1}$ are given. An exothermic peak due to the crystallization of hard segments of the TPU $\left(T_{\mathrm{cc}}\right)$, was observed at $100^{\circ} \mathrm{C}$ in Figure $2 \mathrm{a}$ and $T_{\mathrm{cc}} \mathrm{s}$ of hard segments of the TPU in M-TPU/PETI blends were observed at $140^{\circ} \mathrm{C}$ in Figures $2 \mathrm{~b}, 2 \mathrm{c}$, and $2 \mathrm{~d} . T_{\mathrm{cc}} \mathrm{s}$ of the hard segments of the TPU increased in the M-TPU/PETI blends compared with neat TPU. $T_{\mathrm{cc}} \mathrm{S}$ of the TPU in M-TPU/PETI blends may possibly shift to higher temperature due to exchange reactions during mixing of TPU and PETI. Similar phenomenon in TPU/Polyamide-11 blends was reported by Kim et al. ${ }^{15}$ Figure 3 shows DSC thermograms of the S-TPU/PETI blends obtained by cooling from $220^{\circ} \mathrm{C}$ at $5{ }^{\circ} \mathrm{C} \mathrm{min}^{-1} . T_{\mathrm{cc}} \mathrm{s}$ of the hard segments of TPU's in the blends were observed at $96-99^{\circ} \mathrm{C}$, nearly the same temperatures as for neat TPU. It is not clear why $T_{\mathrm{cc}} \mathrm{S}$ in Figure 3 are scattered slightly depending on PETI content. According to Han, TPUs are not homogeneous at $110-190^{\circ} \mathrm{C}$, but show characteristics of

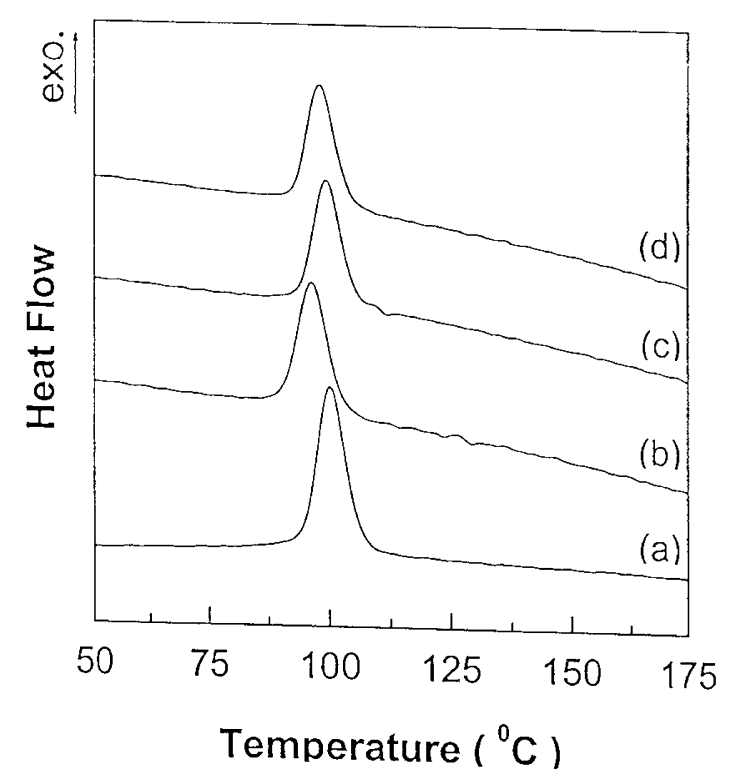

Figure 3. DSC thermograms of various TPU/PETI blends obtained by cooling from $220^{\circ} \mathrm{C}$ at $5{ }^{\circ} \mathrm{C} \mathrm{min}^{-1}$ : (a) TPU; (b) STPU/PETI $=90 / 10$; (c) S-TPU/PETI $=80 / 20$; (d) S-TPU/PETI $=$ $70 / 30$.

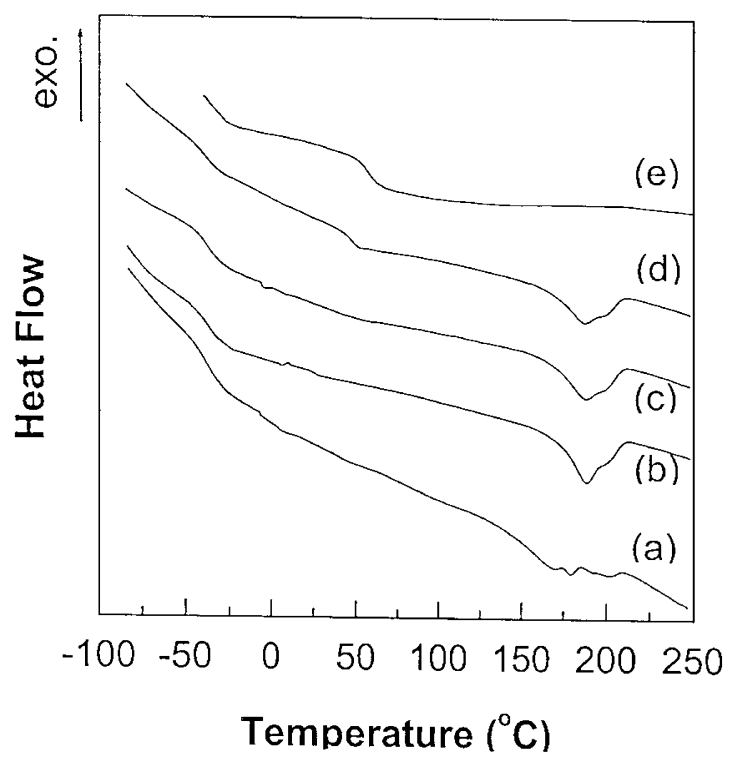

Figure 4. DSC thermograms of various TPU/PETI blends obtained by heating from $-100^{\circ} \mathrm{C}$ at $10^{\circ} \mathrm{C} \mathrm{min}^{-1}$ : (a) $\mathrm{TPU}$; (b) MTPU/PETI = 90/10; (c) M-TPU/PETI = 80/20; (d) M-TPU/PETI = 70/30; (e) PETI.

temperature dependent morphology. ${ }^{16}$ The slight scattering of $T_{\mathrm{cc}} \mathrm{s}$ in Figure 3 may result from slight different morphologies of TPUs depending on PETI contents during cooling crystallization.

Figure 4 shows DSC thermograms obtained by heating M-TPU/PETI blends after cooling crystallization. Enthalpy change due to glass transition of the soft segments of TPU in the blends $\left(T_{\mathrm{gs}}\right)$ was observed around $-47^{\circ} \mathrm{C}$ and endothermic peaks due to melting of the hard segments of the TPU $\left(T_{\mathrm{mh}}\right)$ were observed from 


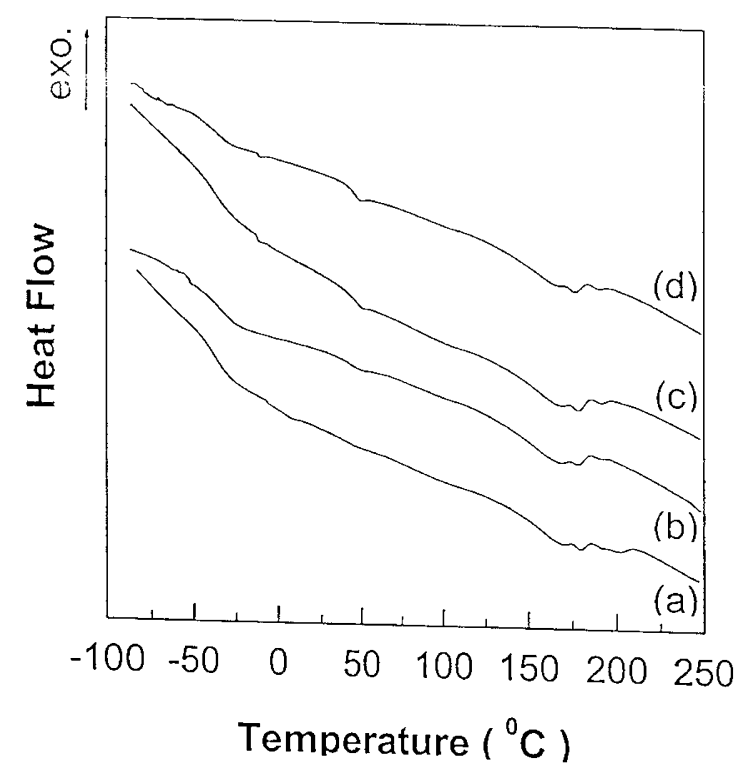

Figure 5. DSC thermograms of various TPU/PETI blends obtained by heating from $-100{ }^{\circ} \mathrm{C}$ at $10{ }^{\circ} \mathrm{Cmin}^{-1}$ : (a) TPU; (b) STPU/PETI $=90 / 10$; (c) S-TPU/PETI $=80 / 20$; (d) S-TPU/PETI $=$ $70 / 30$.

$135^{\circ} \mathrm{C}$ to $205^{\circ} \mathrm{C}$. Figure 4 shows the glass transition of PETI $\left(T_{\text {gp }}\right)$ only in M-TPU/PETI(70/30) blend. In Figure 5, DSC thermograms obtained by heating the STPU/PETI after cooling crystallization are given. Enthalpy change due to glass transition temperatures of the TPU in the blends was observed at $-47^{\circ} \mathrm{C}$ and endothermic peaks were observed from $135^{\circ} \mathrm{C}$ to $205^{\circ} \mathrm{C}$ due to melting of the hard segments of the TPU in the blends. $T_{\mathrm{gs}} \mathrm{S}$ and $T_{\mathrm{mh}} \mathrm{S}$ in Figures 4 and 5 are similar although there are slight differences. Compositions of soft and hard segment domains of the TPU may thus change little even though exchange reactions at the interface of TPU and PETI during melt mixing result in finer dispersion of PETI. Glass transition temperatures of PETIs, $T_{\mathrm{gp}}$, were observed at $31-42^{\circ} \mathrm{C}$ for all S-TPU/PETI blends. The compatibility of TPU and PETI in solution blends may have been lower than that of melt blends in which exchange reactions between TPU and PETI enhance compatibility. This is why the glass transition temperatures of PETI in the STPU/PETI blends are observed clearly compared with those of PETI in M-TPU/PETI blends.

In Figure 6, Arrhenius plots for ionic conductivities of the M-TPU/PETI blends are given. TPU and PETI show change in slope in ionic conductivity around $257 \mathrm{~K}$ and $293 \mathrm{~K}$ respectively. This change for TPU, PETI, and TPU/PETI blends seems related to glass transitions of soft segments of TPU and PETI respectively. Ionic conductivity of M-TPU/PETI blends was higher than for TPU and PETI. This was observed also in S-TPU/PETI blends. According to Okamoto, ionic conductivity of rigid polyelectrolytes increases by

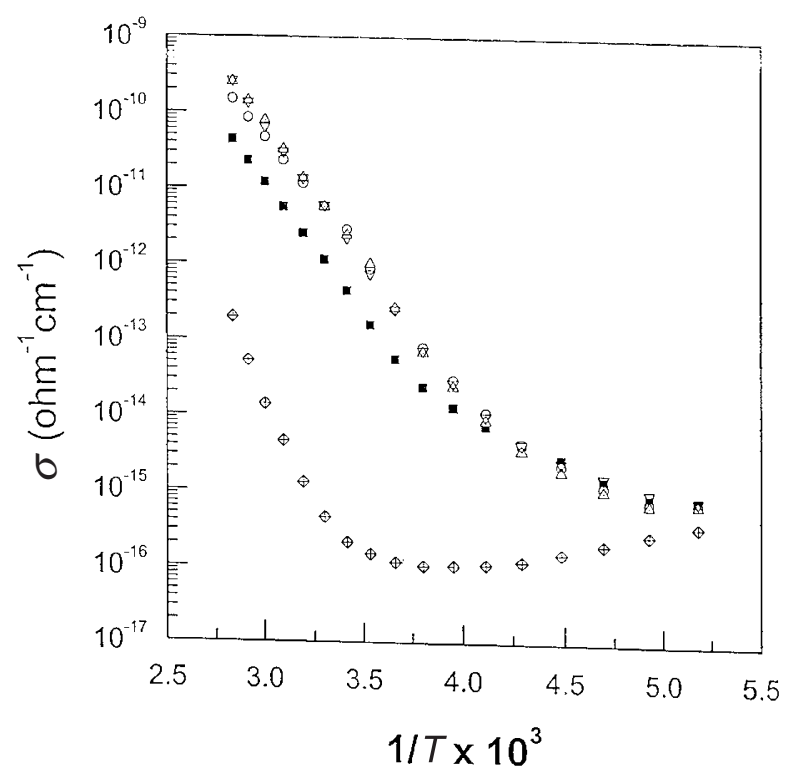

Figure 6. Arrhenius plots of ionic conductivity of $\mathrm{M}$ TPU/PETI blends: $(\boldsymbol{\square})$ TPU; $(\bigcirc)$ M-TPU/PETI $=90 / 10 ;(\triangle)$ MTPU/PETI $=80 / 20 ;(\nabla)$ M-TPU/PETI $=70 / 30 ;(\diamond)$ PETI.

blending of polyelectrolytes and plasticizers. ${ }^{17} T_{\mathrm{gp}}$ s of the blends were lower compared with neat PETI in Figure 4, implying of dissolution soft segments of TPU into PETI due to partial miscibility. Even though $T_{\mathrm{gs}} \mathrm{S}$ of TPU in the blends change hardly, a small amount of PETI may have dissolved in the soft segment domain of TPU due to partial miscibility. Increase of ionic conductivity of the TPU/PETI blends compared with TPU or PETI is attributable to dissolution of PETI in soft segments of TPU which imparts plasticizing effect on ionomeric PETI.

\section{CONCLUSION}

Melt blends of ester based TPU and PETI showed finer dispersion of PETI than corresponding solution blends due to exchange reactions during melt mixing. $T_{\mathrm{cc}} \mathrm{s}$ of the TPU in M-TPU/PETI blends increased while those of S-TPU/PETI blends hardly changed. Exchange products may affect crystallization of hard segments of TPU. Increase of ionic conductivity of TPU/PETI blends compared with TPU or PETI was observed in M-TPU/PETI and S-TPU/PETI blends. Increase of ionic conductivity of the blends may be attributable to PETI dissolved in the TPU rich phase due to partial miscibility, especially in the soft segment rich phase, and glass transition temperature much lower than that of PETI.

Acknowledgments. This study was supported by the Korea Science and Engineering Foundation (KOSEF 97-05-02-02-01-3). 


\section{REFERENCES}

1. C. Hepburn, "Polyurethane Elastomers", 2nd Edition, Elsevier, London, 1991.

2. M. Szycher, "Szycher's Handbook of Polyurethane", CRC Press, London, 1999.

3. D. Dieterich and H. Hespe, in "Polyurethane Handbook", 2nd ed, Oertel Ed., Hanser Publishers, Munich, 1993, chapt. 2.

4. A. Eisenberg and J.-S. Kim, "Introduction to Ionomers", John Wiley \& Sons Inc., New York, N.Y., 1998.

5. C.-W. A. Ng, M. J. Lindway, and W. J. MacKnight, Macromolecules, 27, 3027 (1994).

6. T. L. Boykin, J. Ciacco, and R. B. Moore, Polym. Prepr., (Am. Chem. Soc., Div. Polym. Chem.), 37(1), 717 (1996).

7. G. N. Mahesh, S. Ramesh, and G. Radhakrishnan, Macromol. Rapid. Commun., 17, 73 (1986).
8. Y. Iwatsuki, S. Tsuchida, and S. Yano, Macromol. Chem. Phys., 198, 1787 (1987).

9. Y. Aoki, L. Li, K. Nishimura, and Y. Arashiro, Macromolecules, 32, 1923 (1999).

10. R. S. Porter and L.-H. Wang, Polymer, 33, 2019 (1992).

11. A. M. Kotliar, J. Polym. Sci., Macromolecular Reviews, 16, 367 (1981).

12. K. L. L. Eersels and G. Groeninckx, Polymer, 37, 983 (1996).

13. H. R. Kricheldorf and Z. Denchev, in "Transreaction in Condensation Polymers", S. Fakirov Ed., Wiley-VCH, Weinheim, 1999, chapt. 1.

14. K. Yang and C. D. Han, Polymer, 37, 5795 (1996).

15. B. C. Kim, D. S. Lee, and W. Y. Kim, J. Ind. Eng. Chem., 6, 182 (2000).

16. P. J. Yoon and C. D. Han, Macromolecules, 33, 2171 (2000).

17. Y. Okamoto and M. G. McLin, in "Macromolecular Design of Polymeric Materials", K. Hatada, T. Kitayama, and O. Vogl Ed., Marcel Dekker, New York, N.Y., 1997, chapt. 33. 